\title{
AKTIVITAS RITUAL UMAT HINDU, ANTARA REPRODUKSI IDENTITAS DAN RELIGIOSITAS (Perspektif Teologi Kontemporer)
}

\author{
Oleh: \\ I Gusti Ketut Widana \\ Fakultas Pendidikan Agama dan Seni \\ Universitas Hindu Indonesia \\ Igustiketutwidana1805@gmail.com
}

\begin{abstract}
The influence of modernization in the era of globalization simultaneously also distorts all established order which in the past has been ideal-conceptual. However, now it moves quickly and tends to develop situationally-contextually. This condition finally comes to manifest when the Hindus carry out religious obligations, especially in the form of rituals. It inevitably has been infiltrated by the influence of contemporary lifestyles which is more concerned to the physical/personal appearance and material offerings, rather than spiritual enhancement to achieve spiritual awareness. Thus, the ritual activities appear as a medium of articulation of identity reproduction and have not led to an obsession to strengthen the religiosity.
\end{abstract}

Keywords: ritual, identity reproduction, religiosity, contemporary theology

\begin{abstract}
Abstrak
Pengaruh modernisasi di era globalisasi, secara simultan turut mendistorsi segala tatanan mapan yang di waktu lalu sudah berjalan secara ideal-konseptual, namun kini bergerak cepat dan cenderung berkembang ke arah situasional-kontekstual. Kondisi ini akhirnya menampakkan wujudnya, ketika umat Hindu melaksanakan kewajiban beragama, terutama dalam bentuk ritual, tak dapat dihindari telah disusupi pengaruh gaya hidup kontemporer yang lebih mementingkan penampilan fisikal/personal dan sajian material, daripada peningkatan rohani guna mencapai kesadaran spiritual. Sehingga aktivitas ritual tampak sebagai media artikulasi reproduksi identitas, dan belum mengarah pada obsesi penguatan religiositas.
\end{abstract}

Kata kunci: ritual, reproduksi identitas, religiositas, teologi kontemporer

\section{PENDAHULUAN}

Pada era kebangkitan agama dewasa ini, tantangan besar yang dihadapi umat Hindu tidak lagi berkisar pada usaha untuk menggairahkan kesemarakan aktivitas ritual yang memang sudah semakin marak, tetapi lebih tertuju pada usaha menuju untuk akhirnya mencapai puncak kesadaran spiritual. Sebab, Radhakrishnan, (2003 : 55) menyatakan: "hakikat agama tidak terletak pada dogmadogma dan ritus-ritus serta upacara-upacara menjemukan, tetapi dalam kebijaksanaankebijaksanaan paling dalam dari segala zaman, sanatana dharma, yang merupakan satu-satunya pedoman, bukan semata-mata menyangkut 
kebenaran, melainkan pandangan-pandangan atau pemahaman terhadap kebenaran yang telah diyakini manusia".

Apalagi jika dicermati berdasarkan perspektif 'teologi kontemporer' yang dicetuskan Karl Barth (1919). Bahwa apa yang tampak dalam perilaku keagamaan, dalam hal ini umat Hindu melalui aktivitas ritual (yadnya) ternyata tidak sepenuhnya berpijak murni pada konsep ideal "menghubungkan diri" dengan Ida Sang Hyang Widhi (Tuhan Yang Maha Kuasa) tetapi sudah bergeser dan berkembang berdasar empirisme pemikiran rasional yang tampak melalui interaksi dalam relasi antar manusia lewat ekspresi "kemampuan modal". Sehingga aktivitas ritual umat Hindu pada era kekinian menampilkan kesan sebagai media artikulasi segi-segi material-finansial untuk sebuah eksistensi diri lewat hasrat reproduksi identitas (status sosial, ekonomi, gengsi dan atau gaya hidup), sehingga diasumsikan belum mengarah pada usaha penguatan religiositas atau peningkatan spiritualitas.

Artinya, ketika aktivitas bhakti dalam bentuk ritual dilaksanakan, yang tersaji secara mencolok di depan mata tak ubahnya seperti sebuah acara pementasan di panggung yadnya. Setidaknya hal itu dapat dianalisis dengan menggunakan teori dramaturgi Erving Goffman (1959), bahwa realita demikian digambarkan sebagai sebuah pertunjukkan drama yang terbagi menjadi dua setting; di panggung depan (front stage), semuanya ditampilkan serba baik, serba indah dan maksimal, sementara di panggung belakang (front stage) segalanya kembali kepada hal-hal yang "dasariah" asli tanpa setingan, bergerak apa adanya tanpa rekayasa hingga tampak sisi-sisi paradoks.

Konsekuensinya, aktivitas yadnya umat Hindu tampil dengan setting seperti halnya pentas konsumerisme di panggung ritual. Moment-moment aktivitas ritual yadnya pun berkembang menjadi event seremonial, berlangsung ala festival, seperti karnaval yang tentunya seringkali berbiaya kolosal. Umat pun tatkala terlibat langsung dalam prosesi ritual bergerak dengan mindset seperti rekreasi dengan berbagai ekspresi kreasi, bahkan tidak jarang diselang-selingi acara main judi dan di sana-sini ada pancingan birahi.

Setidaknya realita yang disebut terakhir ini dapat disaksikan melalui tampilan sebagian kaum wanita dewasa berbusana (kebaya) tipis transparan, kain kamben di atas betis (gantut macingcingan), ditambah belahan dada rendah sehingga tampak sensualis bahkan erotis. Kesemua itu menjadikan tuntunan etis, dan landasan filosofis keberagamaan umat kian terkikis oleh gaya trendis dan modis seperti halnya artis selebritis, beserta tingkah lakunya yang semakin narsis bermotif hedonis, sehingga semakin menjauh dari obsesi teologis berbasis religis dan atau spiritualis.

\section{PEMBAHASAN}

Pemikiran teologi kontemporer yang dicetuskan Karl Bath sesungguhnya telah dimulai sejak zaman pencerahan yaitu oleh tokoh filsafat bernama Immanuel Kant. Pada umumnya istilah Teologi Kontemporer disebut juga Teologi Modern yang berbasis historis kritis. Istilah "modern" sering dihubungkan dengan zaman Pencerahan Barat yang menganggap bahwa manusia sudah menjadi matang dan "bebas" untuk berpikir tanpa sanksi atau pengarahan dari luar diri manusia (otoritas di luar diri manusia). Sehingga tidak mengherankan jika motto manusia modern adalah : "beranilah menggunakan pengertianmu sendiri".

\subsection{Dasar Teologi Kontemporer}

Teologi Kontemporer mengembangkan kebebasan berpikir, dan lebih berpijak pada kebenaran kekinian, yang baru bisa percayai atau meyakini sesuatu jika kebenaran itu didasarkan atas prinsip atau asumsi seperti tersaji dalam tabel berikut ini :

\subsection{Kebenaran Kontemporer}

Mengacu dasar teologi kontemporer dengan prinsip dan asumsinya kemudian dipadukan pula dengan pemikiran filsuf Rene Descartes (1596-1650), maka kata kunci teologi kontemporer adalah : "keragu-raguan menjadi prinsip dasar keyakinan bagi manusia modern". Hal ini tampaknya sejalan dengan pandangan Hindu melalui Maharsi Vasistha yang menyatakan : Yukti-yuktam upādeyam vacanam balakād api anyat trṇam iva tvājyam apy uktam padma janmanā, bahwa walaupun kata-kata itu datang dari seorang bocah kecil, jika hal tersebut rasional, harus diterima, dan semua yang 


\begin{tabular}{|c|c|c|}
\hline $\begin{array}{l}\text { Dasar Teologi } \\
\text { Kontemporer }\end{array}$ & Tokoh & Prinsip/Asumsi \\
\hline Rasionalisme & $\begin{array}{l}\text { Aristoteles } \\
\text { (384 SM-322 SM) }\end{array}$ & $\begin{array}{l}\text { Kitab suci tidak menjadi pedoman satu-satunya dalam hidup. } \\
\text { Kehidupan duniawi, tetapi juga berdasarkan ilmu pengetahuan } \\
\text { (rasional-logis) }\end{array}$ \\
\hline Empirisme & $\begin{array}{l}\text { Francis Bacon } \\
(1561-1626)\end{array}$ & $\begin{array}{l}\text { Segala kebenaran hanya dapat diperoleh secara induktif, melalui } \\
\text { pengalaman dan pikiran yang didasarkan atas empiris dan kesimpulan } \\
\text { melalui hal yang khusus kepada hal yang umum. }\end{array}$ \\
\hline Materialisme & $\begin{array}{l}\text { Thomas Hobbes } \\
(1588-1679)\end{array}$ & $\begin{array}{l}\text { Semua/pikiran adalah kesan panca indra. Tidak ada satu konseppun } \\
\text { yang tidak dimulai oleh kesan panca indra. } \\
\text { Seluruh alam semesta adalahkebendaan (material). }\end{array}$ \\
\hline Idealisme & $\begin{array}{l}\text { Thomas Hobbes } \\
(1588-1679)\end{array}$ & $\begin{array}{l}\text { Yang ideal itu akal manusia (rasio), adalah firman Tuhan yang tidak } \\
\text { dapat ditentang. Akal manusia diberi monopoli mencapai pengetahuan } \\
\text { seluruhnya, sedangkan kitab suci hanya berguna untuk menjadikan } \\
\text { manusia taat. }\end{array}$ \\
\hline Eksistensialisme & $\begin{array}{l}\text { David Hume } \\
(1711-1776),\end{array}$ & $\begin{array}{l}\text { Menekankan pada eksistensi indrawi manusia. la juga menentang } \\
\text { mujizat namun tidak meragukan kemungkinan terjadinya mujizat (the } \\
\text { possibility of miracles) }\end{array}$ \\
\hline
\end{tabular}

lainnya yang tidak rasional harus ditolak walaupun hal itu dinyatakan berasal dari Yang Maha Pencipta (Donder, 2015: 45).

Relevansinya dengan artikel ini, perspektif teologi kontemporer mencermati bahwa apa yang dilakukan umat Hindu dalam konteks beraktivitas ritual kekinian, merupakan hasil pertimbangan rasional yang tidak selalu (sepenuhnya) berpijak pada konsep ajaran yang tersurat pada kitab-kitab suci. Terutama ketika terjadinya perubahan mindset umat tatkala melaksanakan kewajiban mayadnya, yang ternyata tidak lepas dari pengaruh perubahan basis ekonomi yang semakin tumbuh menjalar pada gaya hidup masyarakat konsumerisme yang dikembangkan kapitalisme, sebagai bagian dari gaya hidup masyarakat modern, yang didefinisikan sebagai masyarakat konsumsi dalam kemasan serba materi (Ritzer, 2007: 108).

Didukung oleh realita empiris yang memberikan pengalaman bahwa segala kebenaran, selain bersumnber dari kitab suci bagi kalangan penganut agama, juga dapat diperoleh secara induktif melalui pemikiran yang menghasilkan kesimpulan, bahwa dibalik fenomena aktivitas ritual pada era peradaban modern kontemporer yang kian sekuler ini, membawa implikasi berupa terjadinya pergeseran orientasi nilai yang semestinya menekankan pada substansi (tattwa) dan essensi (susila), tetapi yang terjadi dan berkembang adalah pengaruh materialisme melalui tampilan materi dalam kemasan ritual-fisikal.

Melalui analisis perspektif teologi kontemporer, ternyata apa yang disebut kebenaran ideal dalam konteks aktivitas ritual itu tidak lepas dari pertimbangan, pemikiran dan perhitungan akal manusia (rasio), yang oleh Thomas Hobbes dikatakan sebagai firman Tuhan yang tidak dapat ditentang. Bahkan akal manusia diberi monopoli mencapai pengetahuan seluruhnya, sedangkan kitab suci hanya dianggap bermanfaat untuk menjadikan manusia taat. Inilah yang kemudian dapat diasumsikan bahwa aktivitas ritual umat Hindu kekinian berkembang menjadi semacam media artikulasi hasrat unjuk sebuah eksistensi diri sebagai umat beragama yang hidup di tengah hiruk pikuk era kontemnporer.

Sehingga ketika aktivitas ritual umat Hindu dianalisis lebih dalam berdasarkan perspektif teologi kontemnporer, dan kemudian dibedah 
dengan mengacu beberapa teori seperti teori Fenomenologi (Edmund Husserl), teori Motivasi (Abraham Maslow), dan teori Dramaturgi (Erving Goffman), tampak jelas betapa gejala keberagamaan yang muncul ketika umat Hindu melaksanakan kewajiban bhakti lewat ritual, telah membalikkan konsep ideal mayadnya ke dalam konteks sajian material-fisikal. Sehingga aktivitas ritual umat Hindu kekinian lebih tampak sebagai media eksistensi dan aktualisasi diri melalui perhelatan yadnya di panggung ritual, dengan melibatkan banyak pelaku, baik yang murni berdasar konsep parabhakti atau sebaliknya lebih banyak digerakkan semangat aparabhakti (pamer dan pamrih).

Padahal menurut Donder (2013: 513-515) "Ritual is a tool and not a final goal of human being. The final goal of human life is self-realisation, that is, unity with God. Ritual is an important part of religion, especially in the Hindu religion. Because of the rituals' importance, the rituals have survived for so long, but many people still misunderstand the Hindu rituals; and this misunderstanding is due to their ignorance to the rituals, they never wanted to know properly about the rituals.

Terjemahannya :

"Ritual adalah alat dan bukan tujuan akhir manusia. Tujuan akhir kehidupan manusia adalah realisasi diri, yaitu persatuan dengan Tuhan. Ritual adalah bagian penting dari agama, terutama dalam agama Hindu. Karena pentingnya ritual tersebut, ritual tersebut bertahan begitu lama, namun banyak orang masih salah mengerti ritual Hindu; dan kesalahpahaman ini disebabkan oleh ketidaktahuan mereka terhadap ritual, mereka tidak pernah ingin mengetahui dengan benar tentang ritual tersebut.

Untuk itulah, dalam konteks pemahaman pengetahuan tentang ritual yang benar dan berdasar (tattwa-jnana) penting sekali dilakukan pendalaman sisi rasional dibalik konseptual. Menurut Donder (2015: 45) “...para agamawan jangan takut dan merasa berdosa merasionalisasikan atau mengilmiahkan agama. Jangan ada anggapan bahwa mengilmiahkan agama sama dengan mereduksi kesucian agama atau kesakralan agama. Pernyataan ini memberi petunjuk bahwa para agamawan "mau tidak mau harus melakukan interpretasi" terhadap ajaran agama, termasuk yang berkaitan dengan aktivitas ritual (yadnya) sesuai dengan perkembangan ilmu pengetahuan dan percepatan kemajuan teknologi.

Melalui cara interpretasi, lanjut adopsi dan adaptasi konsepsi religi dan teknologi tersebut, dapat membuat ajaran agama yang bersifat abadi (sanatana) akan selalu segar (nutana) sehingga dapat diwaris-teruskan bagi para penganutnya (sentana) dan tetap benar dalam melaksanakannya. Interpretasi tersebut sekaligus juga membuktikan bahwa Tuhan dengan segala ajarannya merupakan sumber dari mana semua ilmu pengetahuan (dan teknologi) itu datang, sebagaimana kitab suci Bhagawadgita, X.4 menyuratkan :

\section{Buddhir jnanam asammohah \\ Ksama satyam damah samah, Sukham duhkham bhawo 'bhawo Bhayam ca'bhayam ewa ca.}

\begin{abstract}
"Intelek, pengetahuan, kesadaran, kesabaran, kebenaran, mengendalikan diri, ketenangan, kesukaan, kedukaan, kelahiran, kematian, ketakutan, keberanian, datangnya dari-Ku" (Pudja, 1981 : 226).
\end{abstract}

Penegasan ini menguatkan pendapat bahwa baik para agamawan maupun para ilmuwan sangat baik jika keduanya mampu memiliki dan memahami pengetahuan secara holistik, baik pengetahuan material kekinian (prawrti jnana) maupun pengetahuan spiritual kerohanian (nirwrti jnana). Karena pada hakikatnya pengetahuan material yang bersifat duniawi dan pengetahuan spiritual yang berorientasi rohani keduanya saling menopang/menunjang satu sama lainnya.

Hal ini sejalan dengan pandangan Puspa (2015 : 229) yang menyatakan, bahwa dalam menjalankan ajaran agamanya umat Hindu di Bali melalui jalan karma dan bhakti sehingga penekanannya dalam bentuk ritual dan simbolik dibandingkan dengan pemahaman dan pengetahuan serta filsafat agama. Dengan demikian agama Hindu oleh banyak pihak dipandang sebagai agama yang lebih 
menekankan pada bentuk ekspresif dibandingkan dengan agama dalam makna pengetahuan atau tattwa.

Perihal bentuk-bentuk ekspresif ini, menyitir pandangan Triguna (1994: 74), memang dikatakan tampak jelas dari rangkaian ritual yang disebutnya sebagai stages along life cyrcle maupun ritual-ritual agama yang ditujukan bagi kepentingan pemujaan dunia bawah maupun atas. Pada pelaksanaan ritual tersebut umumnya umat Hindu di Bali memakai simbol persembahan berupa upakara atau sarana upacara. Bahkan, dalam analisis lanjutan Tary Puspa, ditengarai telah terjadi pergeseran dalam aktivitas ritual umat Hindu, dengan menyatakan bahwa dewasa ini, yang berkembang adalah berbagai bentuk realitas-realitas ritual artifisial, dan berbagai budaya materi serta gaya hidup yang menyertainya yang justru bertentangan dengan hakikat ritual itu sendiri sebagai ruang penyucian jiwa.

Kegiatan ritual keagamaan, sebaliknya telah berkembang menjadi ruang pemanjaan jiwa, lewat berbagai bentuk tanda (sign), citra (image), gaya (style), ilusi, prestise, gaya hidup (lifestyle), dan pesona objek (fetishim) yang ditawarkan di dalamnya. Pengembangbiakan budaya komoditi, budaya pencitraan, dan gaya hidup di dalam masyarakat konsumer atau masyarakat skizofrenik, telah menggiring kegiatan ritual keagamaan ke dalam jagat komoditas atau komodifikasi ritual" yang didorong semangat euforia, sebagaimana disinyalir Puja (2015: 546) yang menerangkan, bahwa euforia ritual yang terjadi di Bali disebabkan oleh rendahnya pemahaman tattwa agama atau masyarakat Bali yang masih banyak belum memahami ajaran agama Hindu secara baik.

Rendahnya pemahaman tattwa itu juga disebabkan oleh hegemoni yang dilakukan sekelompok orang tertentu yang merasa berhak atas pengetahuan mengenai agama, khususnya ritual, yang sejak zaman Veda memang menjadi otoritas atau wewenang kaum Brahmana. Sehingga kehidupan ritual (Panca Yadnya) di Bali saat ini seperti pelaksanaan ritual pada zaman Veda yakni apa kata Brahmana umat tidak berani bertanya dan hanya menuruti apa yang dikatakan oleh Brahmana dan juga tidak ingin tahu mengenai makna ritual yang dilakukan. Hal ini merupakan kemunduran teologi ritual di Bali, padahal pada zaman Kaliyuga yang harus dilakukan adalah japa, namasmarana dan dana punia.

Lebih lugas lagi dikemukakan Sukarsa (2009: vii), dalam bukunya "Biaya Upacara Manusia Bali" : bahwa upacara adat dan keagamaan di Bali adalah sebuah kemeriahan, tidak semata tentang hubungan manusia, alam, dengan Hyang Widhi. Karena sebuah kemeriahan, upacara pun menjadi kesempatan untuk tampil unjuk diri, medan bertemu muka, bertukar badan, Melalui upacara, kekaguman ditumpahkan dan dibiarkan mengalir, sehingga suasana menjadi hiruk pikuk. Upacara adalah pusat keramaian yang selalu dinanti-nanti. Di Bali, menyelenggarakan upacara tidak hanya menjadi keharusan tetapi juga kebutuhan. Ritual pun menjadi sebuah siklus keharusan. Dalam keadaan seperti apapun, saat punya cukup uang atau tidak, upacara harus dilangsungkan. Masuk akal jika kemudian orang Bali menjadi manusia upacara. Untuk itu uang dan materi melimpah harus dikeluarkan, waktu dan tenaga mesti dikorbankan. Upacara - upacara itu menjadi arah dan perubahan pada perilaku manusia Bali.

Atas realita ritual sebagaimana dipaparkan di atas, Jyoti $(2012: 7,9)$ melalui bukunya "Reformasi Ritual, Mentradisikan Agama bukan Mengagamakan Tradisi" memberikan statemen : "...Bali yang sebagian besar penduduknya beragama Hindu ketika masih di dalam tatanan kehidupan agraris berjalan dengan baik bahkan agama Hindu tersebut diperkaya dengan budaya-budaya dari kehidupan agraris itu. Namun ketika kini Bali dilanda oleh pengaruh globalisasi dunia, serta masuk ke dalam era masyarakat industri (pariwisata), maka banyak masalah-masalah yang timbul, khususnya yang berhubungan dengan kehidupan sosial kemasyarakatan, yang memberikan dampak sangat besar pada kehidupan keagaman di Bali, khususnya agama Hindu. Termasuk timbul permasalahan yang menyangkut tentang upakara dan upacara keagamaan yang kelihatan semakin lama makin besar.

Sebaliknya, dengan pergeseran kehidupan agraris menjadi kehidupan industri maka kebutuhan akan bahan upakara kini sukar 
didapatkan di Bali, oleh karena itu kebutuhan tersebut harus di import dari lain daerah, seperti janur, kelapa, buah, bunga, ambu (ron), bambu dan lainnya. Hal ini akan menimbulkan biaya besar yang pada ujungnya akan memberatkan umat Hindu itu sendiri. Bahkan agama Hindu kembali dikambinghitamkan sebagai agama rumit dan mahal, padahal kalau disadari bahwa upacara yang dimaksud itu lebih banyak bernuansa tradisi dan budaya daripada agamanya".

Oleh sebab itu, menurut Jyoti, sangat penting mengetahui hakikat Tuhan dan inti upakara untuk upacara agama Hindu agar betul-betul dipahami benar, sehingga upacara yadnya yang dilaksanakan bisa tepat dan bernilai keagaman dan sakral (religius). Agar agama tidak menjadi beban, tetapi betulbetul dapat menjadi sarana menuju kebahagiaan lahir dan bathin (moksartham jagathita), karena sesungguhnya beragama Hindu dapat dilaksanakan dengan cara mudah dan murah.

Pandangan senada dikemukakan Widana (2015: 103) bahwa sejatinya hakikat ritual adalah simbolisasi tataran filosofis (tattwa) ke dalam praktik yadnya (upacara) yang diharapkan maknanya terimplementasi ke dalam tatanan etika (susila). Ibarat tumbuhan, elemen tattwa (substansi ajaran) adalah pohonnya, praktik upacara/ritual (unsur materi) merupakan bunganya, sedangkan bagian susila/etika (esensi) adalah buahnya.

Analogi ini mengamanatkan bahwa pelaksanaan ritual-yajna baru dikatakan berhasil, bukan karena telah selesai dilaksanakan (sidhakarya) tetapi justru ketika sudah mencapai tujuan (sidhaning don). Bahwa dari praktek ritual-yajna yang sejatinya masih berada di tataran materi (kulit) dapat terus masuk ke dalam substansi (inti) dan kemudian esensi (maknanya) teraktualisasi melalui bentuk-bentuk perilaku yang merefleksikan bahwa memang telah tumbuh berkembangnya semangat kepedulian sosial, terjadinya perbaikan mental, peningkatan akhlak bermoral dan kesadaran spiritual di kalangan umat.

Mencapai tujuan itu, aktivitas keagamaan dalam bentuk ritual-yajna tentunya dapat dijadikan sebagai media pendidikan spiritual, bahwa kegiatan ritual yang dikatakan sebagai kewajiban (swadharma) tidak boleh berhenti di seputaran arena ritual semata (ritual sentris), tetapi harus dipandang dan kemudian dilakoni sebagai eskalator, yang terus bergerak dari anak tangga terbawah (ritual) lalu beranjak naik ke anak tangga berikutnya yaitu dimulai dari terbangunnya semangat kepedulian/solidaritas sosial, lalu terjadinya perbaikan sikap mental (semakin positif dan konstruktif), lanjut peningkatan akhlak bermoral dan akhirnya memuncak pada pencapaian kesadaran spiritual umat.

Berpijak dari harapan ideal yang melekat pada rutinitas praktik aktivitas ritual, dan juga bercermin dari fenomena yang kini telah menjadi realita sosial bahwa semakin hari kian bertambah tinggi intensitas kejadian yang mengingkari makna konsep-konsep ritual, maka dapat dikatakan tampaknya umat Hindu kekinian, kebanyakan baru sebatas melaksanakan ritual (yadnya) sebagai kewajiban simbolik yang masih bersifat ekspresif, dan belum menjadikannya sebagai aktivitas inspiratif dan kontemplatif untuk memotivasi diri mensinergikan antara konsep ritual dalam konteks kebiasaan (habitual) dengan berbuat kebaikan dan kebajikan atau kebijaksanaan (wisdom).

Persoalannya, ketika merujuk pada realita kehidupan, secara mekanik, Tri Kerangka Agama Hindu itu memang bergerak namun sepertinya seringkali berhenti di tingkat Upacara (ritual yadnya), dengan kecenderungan mengesampingkan tuntunan dan tuntutan Susila, dan mengabaikan pendalaman Tattwanya. Konsekuensinya, ekspresi bhakti melalui praktik ritual (Upacara/upakara) memang bertambah kuat dan mantap, namun dalam soal indoktrinisasi dan internalisasi Tattwa (filosofi), apalagi menyangkut implementasi/aktualisasi Susila tampak sekali begitu melemah.

Menggunakan analogi sebutir telur, terungkap bahwa unsur Tattwa yang sesungguhnya adalah 'kuning telur' sebagai elemen "inti" (substansi) agama, pada kenyataannya tidak begitu kuat menstimulus pemahaman atau pendalaman konsep-konsep ajaran, dan malah semakin lemah juga ketika masuk ke tatanan perilaku berke-Susila-an yang merupakan bagian 'putih telur' sebagai elemen "isi" (esensi). Faktanya, yang justru tampak aktif, kreatif dan produktif serta terus bergerak 
secara ekspresif, meski sebenarnya masih berada di tataran simbolik adalah komponen Upacara (ritual yajna) yang sebenarnya merupakan bagian 'kulit' sebagai elemen 'materi' atau kemasan praktik agama Hindu yang sarat simbol dan makna, meski belum tentu bersinergi dalam laksana.

Oleh karena hanya sebagai kulit, seperti ketika hendak memakan telur, kulitnya pasti dikupas lalu dibuang untuk kemudian hanya diambil bagian putih (isi) dan kuning telurnya (inti) untuk dinikmati sebagai asupan gizi pembangun energi (kekuatan dan kesehatan). Apa relevansinya? Jika kita masih tetap berada di bagian kulit saja, memang praktik ritualyadnya akan tetap ajeg lestari, namun belum tentu terjadi pergerakan atau peningkatan ke tataran susila (etika) apalagi tattwa (filsafat). Kecuali akan semakin menampakkan gairah kesemarakan di bagian kemasan (luar) saja dalam bentuk display aneka rupa simbol yang sarat makna meski belum sepenuhnya mengejawantah ke dalam bentuk parilaksana.

\section{PENUTUP}

Tanpa berpretensi memarginalkan praktik ritual yadnya, karena sudah merupakan kewajiban (swadharma), dan semata-mata untuk tujuan umpower (perberdayaan), maka ke depan bentuk dan jenis-jenis ritual yadnya dapat dijadikan inspirasi untuk menstimulus kesadaran diri (self-conscious) agar lebih memaknai simbol-simbol yadnya dalam konteks pengembangan dengan melaksanakan "bentukbentuk lain" yadnya itu sendiri agar semakin bermakna, mengena, dan tentunya berguna bagi semuanya, terutama bagi manusia dan lingkungan (sosial dan alam). Sehingga aktivitas ritual sebagai obsesi membangun spiritualitas atau menguatkan religiositas dapat tercapai, mengalahkan hasrat menjadikannya sebagai media artikulasi reproduksi identitas, dalam segala bentuknya seperti pencitraan, gengsi, atau gaya hidup kekinian yang serba duniawi dapat direduksi atau dieliminasi.

\section{DAFTAR PUSTAKA}

Donder, I Ketut. 2013. "Logical Interpretation of Some Performing Hindu Rituals".

Disertasi. Kolkata India: Rabhindra Bharati University.

Donder, I Ketut. 2015. "Unsur-Unsur Religiositas IPTEK Dalam Ritual Hindu di Bali”. Artikel dalam buku "Konsep dan Praktik Agama Hindu di Bali", oleh Tim Peneliti WHP/ WHC, editor : I Gede Suwantana. Surabaya : Paramita

Goffman, Erving. 1959. The Presentation of Self in Everyday Life. Pennnsylvania: Anchor Books. Jyoti, Ida Rsi Bhujangga Waisnawa Purra Sara Shri Satya. 2012. Reformasi Ritual,

Mentradisikan Agama bukan Mengagamakan Tradisi. Denpasar :

Pustaka Bali Post.

Pudja, G. 1981. Bhagawadgita (Pancama Weda). Jakarta : Mayasari

Puja, I Made Suasti. 2015. "Hambatan Dan Keluhan Umat Hindu Dalam

Melaksanakan Panca Yadnya". Artikel dalam Buku Konsep Dan Praktik Agama Hindu Di Bali, Oleh Tim Peneliti WHP/WHC. I Gede Suwantana (Ed.)Surabaya : Paramita

Radhakrishnan, S. 2003. Religion And Society. Denpasar : Program Magister Ilmu Agama dan Kebudayaan Universitas Hindu Indonesia Bekerjasama dengan Penerbit Widya Guna.

Ritzer, George, Douglas J. Goodman. 2007. Teori Sosiologi Modern, (Edisi Keenam). (Alih

Bahasa: Alimandan). Jakarta. Kencana.

Sukarsa, Made. 2009. Biaya Upacara Manusia Bali. Denpasar. Buku Arti

Puspa, Ida Ayu Tary. 2015. "Reinterpretasi Terhadap Efekitivitas Praktik Beragama Umat 
Hindu Di Bali". Artikel dalam Buku Konsep Dan Praktik Agama Hindu Di Bali, Oleh Tim Peneliti WHP/WHC. I Gede Suwantana (Ed.). Surabaya : Paramita

Triguna, Ida Bagus Gde Yudha. 1994. "Pergeseran dalam Pelaksanaan Agama : Menuju Tattwa. Dalam Dinamika dan Kebudayaan Bali. I Gede Pitana (Ed.). Denpasar: Bali Post

Widana, I Gusti Ketut. 2015. Banten Siap Saji Pentas Konsumerisme di Panggung

Ritual. Denpasar : Pustaka Bali Post 